\title{
Ricardo Palma, clasicismo y modernidad: Estética del nacionalismo y creación verbal'
}

\author{
Manuel Pantigoso Pecero \\ Universidad Ricardo Palma \\ mpantigoso@urp.edu.pe \\ Lima-Perú
}

\section{Resumen}

El trabajo se inicia señalando la actualidad de Palma a través de la ligazón dialéctica muerte-vida. Se destaca su entrañable vínculo con la Biblioteca Nacional, para luego conceptuar la tradición como búsqueda de la identidad nacional, esencia clásica y moderna, y ficción histórica que ella representa.

Palabras clave: permanencia, nacionalismo, tradición, ficción, historia.

\section{Abstract:}

The paper begins by pointing out Palma's actuality through the dialectical link between death and life. It highlights its close link with the National Library, and then conceptualizes tradition as a search for national identity, classic and modern essence, and historical fiction it represents.

Keywords: Permanence, nationalism, tradition, fiction, history.

l Artículo leído en la romería al Cementerio Presbítero Maestro, el 17 de octubre del 2019, conmemorando el Centenario del fallecimiento del tradicionista. 
Manuel Pantigoso Pecero: Poeta, crítico literario y de arte, dramaturgo y maestro universitario, promotor cultural y periodista. Doctor en Literatura y Filología. Doctor en Educación. Doctor Honoris Causa de la URP. Profesor Emérito de la UNMSM. Miembro de Número de la Academia Peruana de la Lengua. Director de la Oficina Central de Extensión Cultural y Proyección Social de la URP y Presidente del instituto Ricardo Palma. 


\section{Introducción}

Fue una impronta clásica con dimensiones modernas el registro literario de Ricardo Palma, y su muerte no acabó verdaderamente con su existencia. Vida y muerte se imantaron más bien para señalar, en la continuidad de ambas, que la gran tragedia de la vida no es la muerte; la gran tragedia es lo que dejamos morir en nuestro interior mientras estamos vivos.

En Palma encontramos, en su vida y en esa continuidad trascendente de su obra dentro de la muerte, un sentido promisorio y esperanzador para acercarse al mundo de los ideales y la justicia. En la lección que rescatamos de la propia plasmación de su obra, hallamos un valor-signo de unidad y de futuro. Él trajo de veras todo el drama del siglo XIX y parte del $\mathrm{XX}$, en donde se desarrolló como militar, periodista y escritor de largo alcance, para alertarnos que en esa época -hasta su fallecimiento- hubo toda clase de conflictos, incertidumbres y temores. Ahora llega a nosotros, en este siglo XXI, con su mensaje de unión, paz y convergencia. Este hombre "matinal" se ha quedado entre nosotros para dar a las nuevas generaciones, desde el futuro permanente que está en la gran obra que lo cobija, una bella lección de fidelidad a la vida y a ese peruanismo esencial que formó parte de su idiosincrasia. Efectivamente, toda su labor artística estuvo asentada en el encumbramiento y la glorificación de nuestro nacionalismo. Por ello, no es casual que las Tradiciones Peruanas continúen siendo motivo de estudio por parte de ilustres investigadores de nuestra literatura e historia, especialmente.

Palma avanza hacia el presente porque su obra lleva el sello de un espíritu clásico que recorrió el Romanticismo, el Costumbrismo, el Modernismo, el Postmodernismo y se asomó inclusive a la Vanguardia. En todo ese proceso y progreso, el equilibrio, la serenidad, la reflexión y la sabia continuidad de los hechos 
pusieron en evidencia una sensibilidad que se renueva, corrige y recrea permanentemente, siguiendo una línea crítica, irónica y retozante, con un basamento humanista ético y estético que transcurre sin tropiezo hasta nuestro tiempo. En toda su obra, su palabra y su estilo se alzan como sujetos que sostienen un sólido "mundo representado" en donde está el Perú, con todas sus riquezas e infortunios. En él, en Palma, se recoge la voz del autor unimismado e imbricado con la voz de los otros, del pueblo en este caso, con su acción y reacción dentro de la sociedad. Al lado de ello está esa función moderna de la literatura hablando al futuro, por su propia cuenta. Heidegger dirá al respecto que "el habla habla". Sobre esto, Mijaíl Bajtín, en Estética de la creación verbal, al hablar de los "géneros discursivos", dice sobre la escritura (p.a):

Todo enunciado, desde una breve réplica del diálogo cotidiano hasta una novela grande o un tratado científico, posee, por decirlo así, un principio absoluto y un final absoluto; antes del comienzo están los enunciados de otros, después del final están los enunciados respuestas de otros (1979, p. 260).

Las respuestas que surgen de sus libros, o "piedrecillas históricas" según sus palabras, serán también de aquellos que vienen después dentro de un continuum histórico en donde el yo y el tú (o los otros) se unimisman. Escuchemos el interior de las propias palabras de Palma, que nos dice (1951, t. II, p. 4):

Mis libros piedrecillas son históricas

Que llevo de mi patria ante el altar.

He cumplido un deber. Saberlo bástame.

Otros vendrán después. Mejor lo harán.

Transcribimos por pertinente, lo que dijimos en el número 17 de Aula Palma: 
Para el budismo, y también para el mundo andino, todos los fenómenos -entre ellos la vida y la muerte- pueden ser vistos como faces críticas de aparición (en estado manifiesto) y de repliegue (en estado de latencia). Estos ciclos se asemejan a los períodos alternados del sueño y la vigilia. La muerte, por ejemplo, es concebida como una fase de descanso y recuperación antes que de una nueva vida, así como el sueño que nos prepara para las actividades del día siguiente. Cuando la muerte se ve desde esta perspectiva, encontramos en ella, al igual que en la vida, un beneficio digno de ser apreciado: el propósito de la existencia, en tanto ciclo eterno de vida y muerte, es sentirnos felices y en paz. Lograr esta condición es la más grande de todas las alegrías. En este sentido, si la vida de Palma fue una de las más intensas, creativas y originales de su tiempo, su muerte fue también fructificante porque él sigue viviendo y manifestándose cada vez que lo visitamos y con él nos admiramos viniendo del pasado. Él está más presente que nunca. Él es ese "puro andar" andino que se dirige sin pausa hacia el futuro (Pantigoso, 2018, p.32).

\section{Escritor de todos los géneros}

Palma fue un escritor romántico, costumbrista, tradicionista, que cultivó prácticamente todos los géneros: poesía, novela, teatro, sátira, crítica, crónicas y ensayos de diversa índole. Pero el género en el que se desenvolvió como pez en el agua, y fue el que él mismo creó, fue la tradición ubicada en el centro del cuento, la crónica y del relato histórico, y aun en el esbozo de la novela breve.

En 1879, cuando Palma ya gozaba de un prestigio literario internacional, empieza la Guerra con Chile. Dos años después, las tropas invasoras toman Lima. Luego incendian la casa 
de Palma, ubicada en el balneario de Miraflores. Perdió su biblioteca personal, donde estaba el manuscrito de su novela "Los Marañones", y sus memorias durante el gobierno de Balta.

Decepcionado y frustrado, el escritor pensó en aceptar una oferta laboral que le hizo el dueño del diario "La Prensa", de Buenos Aires, para que se trasladase a esta ciudad junto con toda su familia a fin de trabajar como redactor literario. Pero el presidente Miguel Iglesias lo convenció para que tomase las riendas de la Biblioteca Nacional del Perú, destruida como consecuencia de la guerra.

Su labor al mando de esta institución, que contaba con un presupuesto famélico, fue encomiable. Palma utilizó su prestigio literario para solicitar a personalidades de diversas partes del mundo la donación de libros, por lo que se ganó el apelativo de "Bibliotecario mendigo".

El 28 de julio de 1884, el escritor inauguró la nueva Biblioteca Nacional del Perú (hoy Gran Biblioteca Pública de Lima). Cuando los chilenos la saquearon ella contaba con 11,256 publicaciones, de las cuales una gran cantidad fue saqueada por el invasor. Ricardo Palma, solo y sin presupuesto, reconstruyó y forjó una nueva colección con 20,000 libros y manuscritos.

En 1912, lejos ya de su labor como bibliotecario y reconocido como el Patriarca de las Letras Peruanas, se retiró a vivir los últimos años de su vida en Miraflores.

Un grave desacuerdo con el primer gobierno de Leguía por la justa defensa de sus fueros le hizo renunciar a la jefatura de la Biblioteca Nacional en 1912, lo que motivó el homenaje y la protesta de la ciudadanía por parte de prestigiosos escritores jóvenes en concurrida velada realizada en el Teatro Municipal. 
Anciano y valetudinario, se retiró por segunda y definitiva vez a Miraflores, desde donde pudo todavía recomponer la Academia Peruana en 1917 y escribir algunas páginas de remembranzas y versos. Murió rodeado de hijos y nietos, en su casa convertida hoy en Museo, el 6 de octubre de 1919.

Fue enterrado con honores correspondientes a un ministro de Estado en el cementerio Presbítero Matías Maestro y se declaró duelo nacional. Javier Prado, historiador, filósofo y abogado, quien era Director de la Academia Peruana de la Lengua y Rector de la Universidad Nacional Mayor de San Marcos, además de Senador por Lima y Presidente de la Comisión de Constitución, dijo ante su tumba: "La más alta personalidad de las letras nacionales se ha desprendido de sus terrenas vestiduras para entrar en el reino de la inmortalidad".

\section{La tradición bajo el liderazgo de Palma: la búsqueda de la identidad nacional}

La expansión de la tradición bajo el liderazgo de Palma comienza desde la primera serie de sus Tradiciones, en 1872. Su antecedente está en el destierro en Chile y en sus contactos con intelectuales de Santiago y Valparaíso, entre diciembre de 1860 y octubre de 1862. Ningún cultor de la Tradición alcanzó lo que Palma entregó al género: gracejo inimitable; participación de la historia y del embozo costumbrista; presencia de la indagación psicológica; escritura sin petulancia, más bien con atractiva llaneza y descubriendo el gusto popular; adecuación de la literatura a las nuevas inquietudes sociales; descubrimiento de las vetas explotables del habla; definición de la propia inquietud americanista; impulso a los escritores hispanoamericanos para trabajar esa rica veta tradicionista del lenguaje que todos llevamos dentro y que a todos nos identifica. 
Palma reanuda la voluntad de construir un género literario nuevo que participe al mismo tiempo de la historia y de la ficción:

En el fondo -señala- la Tradición no es más que una de las formas que puede revestir la historia, pero sin los escollos de esta. Cumple a ella narrar los sucesos secamente, sin recurrir a las galas de la fantasía (...) la historia que se ajusta al espíritu de escuela o de bandería no merece el nombre de tal. La objetividad y la razón analítica son para la Historia; la subjetividad y la fantasía creadora son para la Tradición (Palma, 1968, pp.1474-1475).

La obra de Palma se inserta en la Historia del Perú de los siglos pasados; sin embargo, constituye también un elemento de compresión de los tiempos presentes y de reflexión sobre los tiempos futuros porque instaura, como norma de vida, una intemporalidad que corresponde a la conciencia humana. Por todo esto, él es un clásico que plasma los hechos como una "continuidad esencial en el tiempo", pero es también moderno por su lenguaje que se alimenta de lo popular.

Las Tradiciones fueron publicadas desde 1872 hasta 1919. Comenzó trabajando este género desde la época de los Incas para continuar con la Conquista, el Virreinato, la Independencia, hasta llegar a la República (desde antes de Francisco Pizarro hasta el presidente Leguía, 1919). Con todo ello, Palma se convirtió en el primer escritor peruano que hizo ficción con temas de la historia nuestra, es decir, mediante una impronta totalizadora de los hechos de nuestro pasado. Él fue, sin duda, el padre de la narrativa peruana.

Palma representa el enlace de sus relatos con la cultura popular. Es aquí donde radica la búsqueda de la identidad peruana. Él no es apergaminado. No le gustó el formalismo academicista. Recurría a los refranes, a la memoria popular, a las costumbres 
extraídas del pasado. Él fue en pos de esas frases que en su época estaban en el habla de la cultura popular. El escritor manifestaría, finalmente, que lo que él hacía era comunicar lo conocido por el pueblo, es decir, se fundamentaba en aquella cultura oral que la historia institucionalizada le otorga poco valor. Con él, los tiempos presente, pasado y futuro se habrían de unimismar porque ellos se depositan no en el pensamiento sino en la conciencia, única propiedad espiritual del hombre capaz de reconocerse en sus atributos esenciales.

\section{Palma: clásico y moderno}

A lo largo del tiempo, la obra de Palma ha sabido sortear todo intento de enmarcarla en un solo período o movimiento socioliterario. En sus textos pueden hallarse, por ejemplo, aspectos del Modernismo, en tanto búsqueda de una identidad nacional con lenguaje propio, renovador, de perspectiva abierta, con pretensión moderna y, también, con visos de Vanguardismo debido a la confianza inquebrantable por el futuro de la lengua y de la escritura (recuérdese su lucha ante la Academia Española por incluir en el Diccionario nuevos vocablos americanistas). También hay que anotar su apuesta por el ingenio y el talento en el uso del idioma, como lo dejó escrito a manera de consejo en "Un mozo de chirumen muy sin jugo", poema cuya estructura es un reconocimiento de aquellas formas distintas a las tradicionales. En esta postura se da esa dicotomía tan propia en Palma: clásico por apostar a favor de aquella continuidad esencial de lo peruano; y moderno por estar siempre construyendo el futuro desde la propia palabra.

Los estudios de las tradiciones, los peruanismos que registra, las referencias a la música, danza, religión, enfermedades, hechos sociales y políticos, etc., permiten mostrar un gran 
fresco totalizante e integrador de la sociedad peruana durante la etapa formativa de una identidad nacional proyectada al futuro. Insistimos: Palma crea una identidad peruana fundada en una sensibilidad popular, retozante y celebradora pero, a la vez, crítica de ese pasado y de la realidad por construir.

Bajo el amparo de nuestra Universidad el Instituto Ricardo Palma se congrega hoy día en el Cementerio Presbítero Maestro para recordar, ante su tumba, al gran escritor peruano que aquí descansa desde hace 100 años. Junto a su mausoleo queremos decirle que él -que tanto moldeó nuestra peruanidad-continúa dándonos más luces sobre su vida y su obra aleccionadoras. Y así ha de permanecer, indicándonos que debemos pensarnos como un momento dentro de un largo período, y que para ello es necesario que la historicidad nos acompañe a fin de evitar esa inmediatez que obstruye la memoria y frena la necesaria perspectiva de las cosas.

\section{La ficción histórica como herramienta de trabajo}

Sobre el concepto de historia en Palma se ha reflexionado mucho, y sobre su condición de historiador se han reinterpretado, inclusive, "juicios severos" como el de Manuel González Prada. $\mathrm{Al}$ respecto, la teoría moderna sobre el binomio literaturahistoria, califica de "ficción histórica" el procedimiento por el cual el tradicionista sazonaba con su ingenio e invención los bien documentados hechos y contextos en los cuales basaba sus creaciones narrativas. Precisamente, ese uso libre de la imaginación, la fantasía y el humor dentro de la historia se había de corresponder con una visión crítica de la existencia defectuosa. Se trataría, pues, de la explotación del hecho "real" mediante la llamada "verdad de la imaginación", propia del escritor y, en general, de la literatura en donde la ficción le quita solemnidad al discurso. Esta impronta caló en la presentación 
de hechos "ficcionados", inclusive de su misma vida dentro de sus narraciones.

En general, no se trataba únicamente del ocultamiento o enmascaramiento de la propia existencia sino que, en el estrato textual más profundo, se manifestaba una consideración crítica sobre el país y sobre su historia. Palma asumiría, así, la historia oficial apenas como una de las narraciones posibles de la Historia, es decir, como una forma más de contar y de entender los hechos históricos. Él tomaba en cuenta que la historia es una narración con punto de vista, manejo del tiempo, construcción de un marco, relación de personajes, secuencia de la trama donde suceden hechos, es decir, tal cual los relatos de ficción. La historia peruana es nuestra memoria que usa relatos y anécdotas. Para Palma, esa historia legitima el poder, y por ello, en su condición de liberal, él la cuestiona desde sus cimientos. Esta es la razón por la cual Palma optó por la perspectiva popular en donde el sentido de identidad es más democrático porque, además, permite la irreverencia y la ironía respecto al pasado colonial. Así el tradicionista podía burlarse del poder de lo sagrado, del sistema de la dominación, e ir en contra de la historiografía tradicional, indestructible en el siglo XIX.

Así, pues, las tradiciones serían una reescritura literaria de lo archivado y sagrado, pero con el soporte histórico para otorgar la verosimilitud necesaria. Esta fue la estrategia híbrida de la ficción histórica palmista, la forma como se enfrentó a la ficción realista. Fue la propia voz del narrador, coloquializada por la ficción popular, por la "mentira verdadera" de lo literario que es la que le otorga validez, inclusive a ese lado político de su crítica. 


\section{Bibliografía}

Bajtín, M. (1995). Estética de la creación verbal. México: Siglo XXI.

Holguín Callo, O. (2001). Páginas sobre Ricardo Palma. Lima: Editorial Universitaria de la Universidad Ricardo Palma.

Palma, R. (1951). Tradiciones peruanas, Tomos I-VI. Lima: Cultura Antártica.

Palma, R. (1968). Tradiciones peruanas. Madrid: Ed. Aguilar.

Palma, R. (2005). Epistolario General (1846-1891). Lima: Editorial Universitaria de la Universidad Ricardo Palma.

Pantigoso Pecero, M. (2018). "Ricardo Palma: tres asedios para varias generaciones dentro de una sola vida". En Aula Palma. № 17. Lima: Universidad Ricardo Palma.

Recibido el 20 de octubre del 2019 Aceptado el 30 de noviembre de 2019 


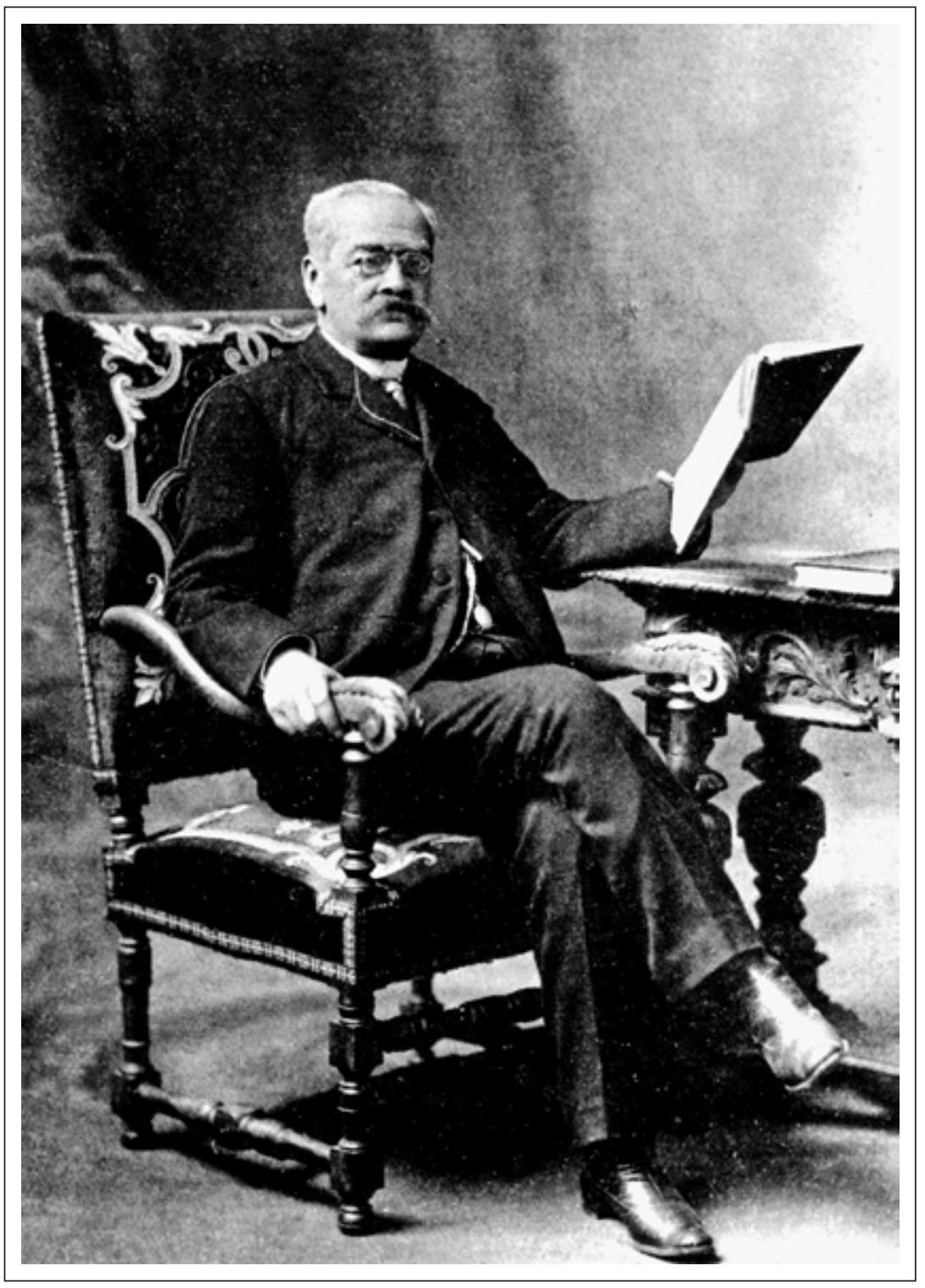

